UNIVERSITÀ CATTOLICA DEL SACRO CUORE

Dipartimento di Economia e Finanza

\author{
Working Paper Series
}

Price Discrimination in Asymmetric Industries:

Implications for Competition and Welfare

Hinnerk Gnutzmann

Working Paper n. 19

November 2014

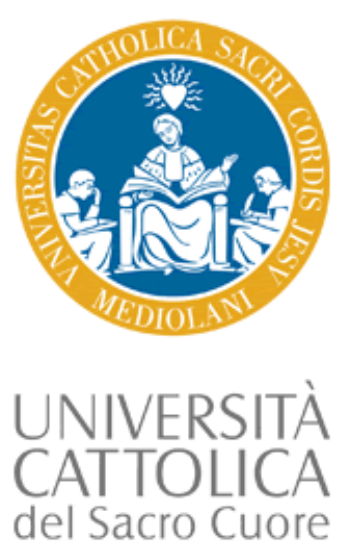




\title{
Price Discrimination in Asymmetric Industries: Implications for Competition and Welfare
}

\author{
Hinnerk Gnutzmann \\ Università Cattolica del Sacro Cuore
}

Working Paper n. 19

November 2014

\author{
Dipartimento di Economia e Finanza \\ Università Cattolica del Sacro Cuore \\ Largo Gemelli 1 - 20123 Milano - Italy \\ tel: +39.02.7234.2976 - fax: +39.02.7234.2781 \\ e-mail: dip.economiaefinanza@unicatt.it
}

The Working Paper Series promotes the circulation of research results produced by the members and affiliates of the Dipartimento di Economia e Finanza, with the aim of encouraging their dissemination and discussion. Results may be in a preliminary or advanced stage. The Dipartimento di Economia e Finanza is part of the Dipartimenti e Istituti di Scienze Economiche (DISCE) of the Università Cattolica del Sacro Cuore. 


\title{
Price Discrimination in Asymmetric Industries: Implications for Competition and Welfare
}

\author{
Hinnerk Gnutzmann ${ }^{\text {负 }}$ \\ Department of Economics, Universita Cattolica del Sacro Cuore \\ Via Necchi 5, 20123 Milan, Italy
}

\begin{abstract}
Price discrimination by consumer's purchase history is widely used in regulated industries, such as communication or utilities, both by incumbents and entrants. I show that such discrimination can have surprisingly negative welfare effects - even though prices and industry profits fall, so does consumer surplus. Earlier studies that did not allow entrants to discriminate or assumed symmetric firms yielded sharply different results, the pro-competitive effect of price discrimination are stronger in these settings. Imposing a pricing constraint on incumbent's discrimination leads the entrant to discriminate more heavily, but still improves both consumer and producer welfare.
\end{abstract}

Keywords: History-based price discrimination, asymmetric price discrimination, switching cost

JEL: L13 L41

\section{Introduction}

"Enjoy a 50\% discount - only when switching from a competitor". Such history-based price discrimination (Gehrig et al., 2012) is often used as a pricing strategy in subscription markets from software ${ }^{1}$ to communications. For example, Italian mobile incumbent TIM offers one month free and extra $4 \mathrm{G}$ to switching consumers, while competitors Tre and WIND reward

\footnotetext{
${ }^{\star 2}$ E-Mail address: hinnerk.gnutzmann@unicatt.it. Telephone: +393738230841

${ }^{1}$ For example, Microsoft, an entrant in the web-based customer relationship management software (CRM) market, in 2010 offered a $\$ 200$ discount per user for firms switching from incumbent Salesforce, who made no similar offer to Microsoft's consumers (Rosoff, 2010)
} 
switchers with a permanent $50 \%$ discount on the monthly bill ${ }^{2}$. Naturally, the competitive and welfare effects of such price discrimination in oligopolies are of intense policy interest to regulators and competition authorities alike (c.f. Swedish Competition Authority (2005, chapter 1)): is price discrimination a symptom of a competitive market? Does it lead to exploitation of certain consumer groups? Can constraints - or indeed outright bans of price discrimination raise consumer surplus or social welfare? And what about industry profits?

This paper shows that history-based price discrimination in asymmetric industries can have surprisingly negative welfare implications. I study a duopoly with two consumer groups, "old" consumers who previously purchased from the incumbent firm and face switching cost, and "new" consumers who do not. Crucially, I allow both entrant and incumbent to use price discrimination, which is the practically relevant case in many markets. Then price discrimination harms consumer welfare - even though prices, on average, fall. This stands in contrast to symmetric models, which inform many policy debates, where consumers typically benefit from pro-competitive effects of price discrimination ${ }^{3}$. Furthermore, industry profits suffer from discrimination.

I contribute to the literature in three ways. First I show that even "procompetitive" price discrimination - in the sense of falling prices - can harm consumers, an observation that appears to have been so far overlooked, but has important implications for empirical research. Second, entrants can come to know a potential consumer's purchase status with the incumbent through suitably designed pricing menus; thus the two-sided price discrimination observed in practice is firmly rooted in theory. Finally, asymmetric regulation of incumbent's price discrimination endogenously leads to entrant to discriminate more heavily, a "see-saw" effect, but still improves consumer and social welfare.

A large theoretical literature studies price discrimination based on purchase status, surveyed in Fudenberg et al. (2006) and Esteves (2009). As in Thisse and Vives (1988), these models typically show that price discrimination leads firms to compete more fiercely over each marginal consumer; thus,

\footnotetext{
${ }^{2}$ Table 1 documents the use of history-based price discrimination in European mobile markets

${ }^{3}$ See e.g. Papandropoulos (2007) for an exposition of this view from a European perspective
} 
price discrimination is pro-competitive and benefits consumers, although social welfare costs of discrimination are well known (e.g. due to excessive switching, as in Chen (1997)). Fundamentally, the pro-competitive effect is due best-response asymmetry Corts (1998), i.e. each firm wanting to discriminate in favor of consumers currently buying from a competitor - leading to a prisoner's dilemma-like dynamic of falling prices for all. But, as the present paper shows, best response asymmetry need not arise in asymmetric industries; hence the competitive and welfare effects are drastically different.

The effects of price discrimination in asymmetric industries are less well explored. Gehrig et al. (2011) study a model closely related to mine, but a priori constrain the entrant to uniform pricing; I show that entrants can in fact elicit such information through second-degree price discrimination, and allowing for this reverses their social welfare result. In Chen (2008), an incumbent has a captive segment and faces entry only in a competitive segment; price discrimination by the entrant is thus precluded. He shows that allowing the incumbent to discriminate tends to benefit consumers through lower prices - as long as it not cause the competitor to exit. Bouckaert et al. (2013) study a two-period model, where an incumbent has a sheltered segment; both firms compete over a competitive segment a la Fudenberg and Tirole (2000). They show that price discrimination can facilitate entry and raise welfare when the monopolistic segment is small.

Policy interventions to limit price discrimination of the incumbent raise consumer surplus and social welfare. While uniform pricing by all firms may be necessary to achieve a first best, competition authorities and regulators typically have the most influence over incumbents, not entrants. In the case of on-net/off-net price discrimination, the Colombian telecoms regulator moved to impose a cap on price discrimination by the incumbent, leaving entrants free to discriminate; while in Portugal, the incumbent network proposed a voluntary commitment to abstain from on-net/off-net price discrimination as a merger remedy (see Telecommunications Management Group, Inc. (2011, sections 3,7) respectively). Since regulation is often asymmetric (Peitz, 2005), I follow Bouckaert et al. (2013) and focus on asymmetric pricing constraints affecting only the incumbent. Precisely, the policy instrument in my model is a cap on the incumbent's price wedge between old and new consumers. 


\section{Model}

I consider a duopoly, with incumbent - firm I - located at point 0 of the Hotelling line, and the entrant $E$ at point 1 . Thus, entry has already happened: the concern of the analysis is the asymmetry of market shares. There is a unit mass of consumers is distributed uniformly on the Hotelling line, with position indexed by $x$ and partitioned - independently of their location into two groups: old consumers, with mass $1-\theta$, have all purchased from the incumbent in a past period. These consumers would incur a switching cost $s$ if they moved to the entrant. The remaining mass, $\theta$, are new consumers just joining the market, who obviously do not face any switching costs. The utility of consumption is $\beta$, sufficiently high to ensure full market coverage. Consumers face constant transportation cost per unit of distance $t$. I assume that $0<s<3 t$, which ensures the old segment is potentially competitive.

Both firms engage in price discrimination. Incumbent I has a "customer database", containing the identities of all old consumers. Absent regulation, she can thus engage in third degree price discrimination and charge prices $p_{O}^{I}$ and $p_{N}^{I}$ respectively. The entrant $\mathrm{E}$ may engage in second degree price discrimination, targeting price $p_{O}^{E}$ to old and $p_{N}^{E}$ to new consumers. Old consumers can reveal their status if they so choose; for this to be incentive compatible, we must of course have $p_{O}^{E} \leq p_{N}^{E}$. The equilibrium prices are determined in a simultaneous pricing game.

The marginal consumers are hence given by:

$$
\begin{aligned}
& \tilde{x}_{O}= \begin{cases}\frac{p_{O}^{E}-p_{O}^{I}+t+s}{2 t} & \text { if } p_{O}^{E} \leq p_{N}^{E} \\
\frac{p_{N}^{E}-p_{O}^{I}+t+s}{2 t} & \text { otherwise }\end{cases} \\
& \tilde{x}_{N}=\frac{p_{N}^{E}-p_{N}^{I}+t}{2 t}
\end{aligned}
$$

Both firms face constant and common marginal cost, normalised to zero. There is no fixed cost; hence firms' profit functions are given by

$$
\begin{aligned}
\pi^{I} & =(1-\theta) \tilde{x}_{O} p_{O}^{I}+\theta \tilde{x}_{N} p_{N}^{I} \\
\pi^{E} & =(1-\theta)\left(1-\tilde{x}_{O}\right) p_{O}^{E}+\theta\left(1-\tilde{x}_{N}\right) p_{N}^{E}
\end{aligned}
$$

Solving the model yields the following unique equilibrium: 
Proposition 1. There is a unique equilibrium such that

(a) Old consumers $\tilde{x}_{O}^{*}<\frac{1}{2}+\frac{s}{6 t}$ and new consumers $\tilde{x}_{N}^{*}<\frac{1}{2}$ purchase from the incumbent; all others from the entrant

(b) The incumbent charges $p_{O}^{* I}=t+\frac{s}{3}$ to old consumers, and the entrant's switching price is $p_{O}^{* E}=t-\frac{s}{3}$. Both firms charge $p_{N}^{* I}=p_{N}^{* E}=t$ to new consumers

Proof. All proofs are collected in the appendix

The equilibrium replicates stylized facts discussed above well. First, the incumbent remains dominant in the market, because of a majority share among old consumers. Old consumers staying with the incumbent pay the highest price, and switchers pay the least. New consumer prices lie between these extremes. By construction, the incumbent does not make switching offers, which also agrees with the stylized facts.

Result 1. In equilibrium, both entrant and incumbent engage in price discrimination

The equilibrium is unique, and has the incentive compatibility constraint on the entrant non-binding. Although the incumbent charges a higher price to old consumers, the entrant in equilibrium wants to give a sufficiently large switching discount to old consumers vis-a-vis new consumers and thus induces them to reveal their status. Thus, in the switching cost setting, the entrant's lack of data does not have a strategic effect ${ }^{4}$.

\section{An Asymmetric Pricing Constraint: Strategic Effects}

Price discrimination refers to price differences that cannot be attributed to marginal cost differences. Given the assumptions on marginal cost, we can identify the price wedge $\delta_{i}=\left|p_{O}^{i}-p_{N}^{i}\right|$ as our measure of price discrimination. Let $\Delta$ denote the constraint imposed on the incumbent's price discrimination:

$$
\left|p_{O}^{I}-p_{N}^{I}\right| \leq \Delta
$$

This construction effectively turns price discrimination into a continuous variable, as in Layson (1998) for the monopoly case. It clearly encompasses

\footnotetext{
${ }^{4}$ Geradin and Kuschewsky (2013) discuss cases where data ownership may affect competition
} 
the polar cases $\Delta=0$, i.e. a complete ban on price discrimination, as well as absence of any regulation $(\Delta=\infty)$, while also allowing for intermediate policies that merely place a cap on the price wedge (as in the Colombian example discussed in the introduction). In contrast to the more standard "binary" approach (i.e, considering only the extreme cases), this approach also has a technical advantage: it enables the use of Leibnitz' rule to precisely disentangle the various welfare effects.

Given the policy adopted by the regulator, the incumbent's problem now is to maximise equation 3 subject to this constraint. This leads to the following unique equilibrium:

Proposition 2. Only if $\Delta \in\left[0, \frac{s}{3}\right]$, the pricing constraint binds. Then,

(a) Old consumers with $\tilde{x}_{O}^{*} \leq \frac{1}{2}+\frac{s(\theta+2)}{12 t}-\frac{\Delta \theta}{4 t}$ and new consumers with $\tilde{x}_{N}^{*} \leq$ $\frac{1}{2}+\frac{s(\theta-1)+3 \Delta}{12 t}-\frac{\Delta \theta}{4 t}$ purchase from firm $I$, and all others from firm $E$

(b) Firm I sets prices $p_{O}^{* I}=\frac{s(1-\theta)}{3}+\Delta \theta+t, p_{N}^{* I}=\frac{s(1-\theta)}{3}-\Delta(1-\theta)+t$. Firm $E$ 's prices are $p_{O}^{* E}=\frac{(3 \Delta-s) \theta}{6}-\frac{s}{3}+t$ and $p_{N}^{* E}=\frac{s(1-\theta)}{6}-\frac{\Delta(1-\theta)}{2}+t$

Under regulation, old consumers pay less and are more likely to buy from the incumbent, vice-versa for new consumers. Figure 1 visualises the comparative statics, with dotted lines indicating pre-regulation prices and market shares and solid lines indicating outcomes for binding pricing constraints.

i. Old
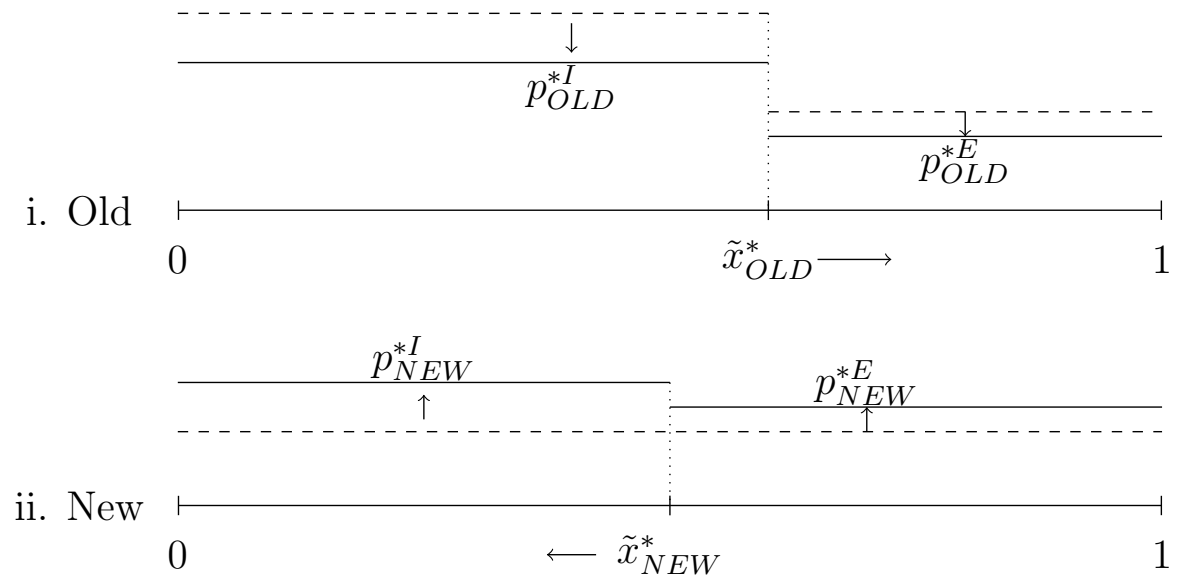

Figure 1: Comparative Statics of Regulation

Regulation of the incumbent induces the entrant to engage in stronger price discrimination. Indeed, under the equilibrium prices given in proposi- 
tion 2 , the entrants price discrimination behaves as

$$
\delta_{E}=p_{N}^{* E}-p_{O}^{* E}=\frac{s-\Delta}{2}
$$

which is decreasing in $\Delta$. Tighter regulation - a lower delta - thus promotes entrant's price discrimination. This illustrates that the assumption of uniform pricing by the entrant in Gehrig et al. (2011) may be problematic when simulating the effect of a possible ban on incumbent price discrimination. Summarising,

Result 2 (See-Saw Effect). As the incumbent's price discrimination is constrained, the entrant's price discrimination becomes stronger

Such counter-intuitive, indirect effects of interventions are well-known in other contexts of the regulation literature, e.g. the "waterbed effect" in Inderst and Valletti (2011). Importantly in view of proposition 2, the asymmetric pricing constraint does not monotonically move the industry closer to equal pricing, which will have welfare implications to be discussed.

It remains to investigate the further properties of the equilibrium. First, consider market shares. The firms' market shares move in opposite directions in each segment. In fact, a calculation shows that - given the linear structure of the model - regulation merely shifts market shares between segments:

$$
(1-\theta) \tilde{x}_{O}+\theta \tilde{x}_{N}=\frac{1}{2}+\frac{s(1-\theta)}{6 t}
$$

which does not depend on $\Delta$. Hence,

Result 3. Overall market shares are invariant to the pricing constraint

In Gehrig et al. (2011), the same result holds. However, quantitatively, the changes in market share are smaller in the present model - since the entrant price in each segment moves in the same direction as the incumbent's, the shift in marginal consumers becomes smaller. Importantly, this shows that one benefit often conceded to bans on price discrimination - that they allow smaller players to increase their market share - need not always arise.

\section{Welfare and History-Based Price Discrimination}

History-based price discrimination has surprisingly negative welfare consequences in this model. As the incumbent's pricing constraint $\Delta$ is relaxed, 
old consumers face rising prices and increased switching rates; while new consumers benefit from lower prices and a more efficient brand allocation, the corresponding gains are small. In fact, even though price discrimination is pro-competitive - prices fall on average - consumer welfare falls under price discrimination. Due to the pro-competitive effect, industry profits also fall under price discrimination. Hence, price discrimination leads to a "lose-lose" that harms social welfare.

First, some notation. Let $v_{j}(x ; p)$ denote the indirect utility function of a consumer of location $x$ when facing prices $p$, where $j=\{O L D, N E W\}$. Consumer surplus can be written as the integral of indirect utility over all consumers:

$$
C S=(1-\theta) \underbrace{\int_{0}^{1} v_{O}(x ; p) d x}_{C S_{O}}+\theta \underbrace{\int_{0}^{1} v_{N}(x ; p) d x}_{C S_{N}}
$$

The welfare effects of price discrimination on consumers can be derived conveniently through Leibnitz' rule. The expression of interest being $\frac{d C S}{d \Delta}$, a key advantage of focusing on an interval for pricing constraints instead of a ban/no regulation setting, one can disentangle quite precisely the different forces acting on welfare. I proceed analogously for social welfare and producer surplus. These calculations yield

Result 4. Price discrimination harms consumer welfare. There is a distributional conflict between old consumers - who face rising prices - and new consumers, who gain from lower prices in a discriminatory setting. However, benefits to new consumers are small, so consumers as a whole lose under price discrimination

The harmful effects on consumer surplus are entirely driven by price changes on extra-marginal consumers. This is a consequence of the envelope theorem: a small relaxation in the pricing constraint does not affect the welfare of the marginal consumer between incumbent and entrant in either segment. Given a small relaxation of the constraint, incumbent's prices for the $1-\theta$ mass of old consumers rise at rate $\theta$, and fall at rate $1-\theta$ for new consumers. The entrant's prices move in the same directions, but at half the rate - a consequence of the linear Hotelling structure of the model. But crucially, since old consumers purchase from the incumbent at a higher rate than new ones, the net welfare change is negative: losses to old consumers weigh more heavily, and hence consumer surplus fall. 
The negative consumer surplus result is not typical of the literature. In Chen (1997) or Fudenberg and Tirole (2000), price discrimination leads to "all out" competition, i.e. all prices falling; thus consumers benefit. But these results are derived in symmetric settings. In the domain of asymmetric models, Chen (2008) shows that allowing incumbents to discriminate can also intensify competition and benefit consumers, as long as it does not cause exit. However, in monopoly settings, price discrimination often facilitates exploitation of consumers (Layson, 1998). Thus one would expect very asymmetric industries to approximate this result, as indeed is the case in Gehrig et al. (2011).

A regulator may, for policy reasons, favor "vulnerable" consumer groups. Hviid and Price (2012) discuss the case of the UK energy market, where the protection of "vulnerable" consumers is part of the statutory mandate of regulator Ofgem. In particular, such consumers are - for various reasons often not able to switch. As constraints on price discrimination most strongly reduce the incumbent's price charged to old consumers, i.e. non-switchers, this adds a further equity rationale to such a policy.

Result 5. Price discrimination is "pro-competitive", and reduces industry profits. Discrimination enhances the profitability of the incumbent while diminishing that of the entrant.

Price discrimination leads to falling average prices. As $\Delta$ is relaxed, the incumbent raises prices for old consumers while lowering them for new ones; due to strategic complementarity, the entrant's prices move in the same direction. These price movements benefit incumbent profitability - who can more effectively exploit old consumers under discrimination - and harm the entrant; overall, industry profits fall. In contrast, in Gehrig et al. (2011), price discrimination does not affect entrant prices and profits; only the incumbent benefits from discrimination, and accordingly industry profits rise. Symmetric models often have profits of all firms falling, e.g. Chen (1997).

Excessive switching under price discrimination causes social welfare to fall:

Result 6. Social welfare falls under price discrimination, because the losses due to excessive switching outweigh gains from improved brand allocation of consumers

Social welfare effects are driven entirely by marginal consumers. Price discrimination increases switching rates, i.e. the marginal old consumer turns 
to purchasing from the entrant as $\Delta$ is relaxed. This affects welfare positively through the change in brand allocation - since the marginal consumer $\tilde{x}_{O}>$ $1 / 2$, the marginal consumer's preferred brand is that of the entrant - and negatively through the increase in switching cost $s$. Among new consumers, the incumbent's market share rises; this is good for welfare, since the marginal new consumer indeed prefers the incumbent's brand $\left(\tilde{x}_{N} \leq 1 / 2\right)$. However, observe that the overall welfare effect of price discrimination on social welfare is negative: the deadweight loss due to switching outweighs the positive effects of better brand allocation. The negative social effects of switching are well-known in the theoretical literature and also arise in symmetric settings, c.f Chen (1997). Interestingly, Gehrig et al. (2011) find that history-based price discrimination increases social welfare. In their model, the lack of entrant's price response discrimination drives increases in producer surplus under discrimination; these outweigh the costs to consumers.

Throughout the analysis, I have assumed that the segment of "old" consumers is potentially competitive, i.e. switching costs are not too high. This assumption is supported by evidence, e.g. Hviid and Price (2012) report that half of old consumers in UK energy market switched within a decade. However, comparison with results for the "sheltered" case, as in Bouckaert et al. (2013), is very interesting. As the authors show, when the sheltered segment is large, an incumbent constrained to uniform pricing raises prices in the competitive segment, causing a loss of consumer and social welfare overall.

To conclude, the model implies that history-based price discrimination may have very negative consequences for consumers and producers alike. Indeed, a ban on incumbent price discrimination would clearly be welfare optimal in this setting.

\section{Policy Implications}

Price discrimination can take a myriad of forms, and effects can differ greatly depending on industry structure and the precise pricing strategy employed. Accordingly, as Geradin and Petit (2005) point out, price discrimination is one of the most complex areas of European competition law and a "case-by-case" approach is often required. In this discussion, I demonstrate the relevance of the precise setting studied in the model. Moreover, I argue that the main trade-offs in which the policy debate is often framed exploitation of consumers versus exclusion of smaller firms - is incomplete; 


\begin{tabular}{|c|c|c|c|c|c|}
\hline Country & Operator & Type & Share & Offer? & Details \\
\hline Germany & T-Mobile & Incumbent & $33 \%$ & No & \\
\hline Germany & Vodafone & Entrant & $30 \%$ & No & \\
\hline Germany & E-Plus (Base) & Entrant & $21 \%$ & No & \\
\hline Germany & $\mathrm{O} 2$ & Entrant & $17 \%$ & Yes & $60 €$ one-time discount \\
\hline Italy & Tim & Incumbent & $38 \%$ & Yes & 1 month free $+1 \mathrm{G}$ extra internet \\
\hline Italy & Vodafone & Entrant & $26 \%$ & No & \\
\hline Italy & Wind & Entrant & $25 \%$ & Yes & $50 \%$ permanent discount \\
\hline Italy & Tre & Entrant & $11 \%$ & Yes & $50 \%$ permanent discount \\
\hline France & Orange & Incumbent & $41 \%$ & No & \\
\hline France & SFR & Entrant & $32 \%$ & Yes & $50 €$ one-time discount \\
\hline France & Bouygues & Entrant & $17 \%$ & Yes & $50 €$ one-time discount \\
\hline France & Free Mobile & Entrant & $9 \%$ & No & \\
\hline Spain & Movistar & Incumbent & $42 \%$ & No & \\
\hline Spain & Vodafone & Entrant & $29 \%$ & No & \\
\hline Spain & Orange & Entrant & $23 \%$ & No & \\
\hline Spain & Yoigo & Entrant & $6 \%$ & Yes & $5 €$ one-time discount \\
\hline
\end{tabular}

Figure 2: Switching Offers in European Mobile Markets ${ }^{5}$

one needs to take into account deadweight welfare losses too. This angle may lead to a more positive evaluation of constraints on price discrimination, even in competitive settings.

History-based price discrimination is prevalent in key European mobile markets, as the pricing data in table 1 show. In all markets studied, at least one firm engages in this form of price discrimination. There is considerable variance in the use of switching offers: in Italy, three out of the four main networks use price discrimination, including the incumbent - while in Germany and Spain, only the smallest networks make switching offers. Clearly, the data show that one cannot restrict attention to discrimination of the incumbent only when analyzing these markets. Moreover, the discounts offered to switching consumers are often very significant, such as a permanent $50 \%$ discount on the monthly bill; highlighting the importance of switching to how these markets work. 
Price discrimination is often viewed through the lens of exploitation vs. exclusion. As Karlinger and Motta (2012) show, price discrimination typically leads to lower prices for consumers. This may promote consumer surplus, as long is it does not cause exit. Similarly, in Chen (2008), consumers in the competitive segment buy more units when price discrimination is allowed, driving another welfare gain. This analysis has been influential on policy, with e.g Papandropoulos (2007) emphasising the need for "caution" when limiting price discrimination unless exclusion is a concern. But with switching cost, as the present analysis shows, lower average prices do not even imply higher consumer surplus: consumers may need to expend more effort on switching that renders the gains void. Especially in subscription markets, such as regulated utilities, the existence of switching friction may indeed call for less price discrimination than would otherwise be the case.

It is intuitive that asymmetric industries call for asymmetric regulation. In an incumbent-entrant setting, Peitz (2005) demonstrates that asymmetric access charge regulation leads to better outcomes than symmetric regulation. The current European regulatory framework favors wholesale price regulation over retail price regulation. But Hoernig et al. (2014) demonstrate, uniform pricing constraints at the retail level can further improve social welfare after access charge regulation has already been implemented. Hoernig (2008) shows uniform pricing constraints may increase social welfare, but can cause a loss of consumer surplus due to higher prices.

Empirically, the track record of uniform pricing constraints has been uneven. Consider the use of non-discrimination clauses in the UK retail energy sector (Hviid and Price, 2012). Here, individual regions are well described by the "inherited monopoly" model, with the previous regional incumbent in a dominant position. In 2009, the regulator introduced a clause requiring firms to charge uniform markups at the national level; Hviid and Price (2012) argue that best response asymmetry holds nationally in the UK energy retail market, and hence explain why this regulation led to higher prices across all markets. An alternative policy would be to require uniform pricing only in those regions where the incumbent is dominant, leaving pricing unconstrained in each firm's "weak market". The present analysis suggests that

\footnotetext{
${ }^{5}$ Pricing data collected from networks' websites between 22-26 November 2013. Subscriber shares obtained from http://en.wikipedia.org/wiki/List_of_mobile_ network_operators_of_Europe and national sources cited therein.
} 
such an alternative policy may have benign welfare consequences.

\section{Conclusion}

As subscription markets are growing, history-based price discrimination and its associated complexity of pricing strategies is becoming ever more important. This paper studied an empirically important case of such price discrimination - an asymmetric industry, where both incumbent and entrant may use history-based price discrimination - contributing to the literature on asymmetric price discrimination (Chen (2008),Bouckaert et al. (2013), Gehrig et al. (2011)). Regulation of the incumbent causes entrants to discriminate more heavily, and bans on price discrimination increase average prices and hence industry profits.

But even "pro-competitive" price discrimination can harm consumers. When switching cost is important, the increased competitive intensity under discrimination may not be enough to compensate for the increased effort consumers have to exert to claim the lower prices. Moreover, it is already well established in the literature that price discrimination can harm social welfare, due to excessive switching. Interestingly, lower prices do not necessarily benefit anyone. Uniform pricing constraints on an incumbent may thus promote social welfare.

\section{Appendix}

This appendix collects the proofs of the statements in the main text. Proof of Proposition 1: Equilibrium requires simultaneous maximisation of equations (3-4). Consider first the case $p_{O}^{E}<p_{N}^{E}$. This yields the first-order conditions:

$$
\left[\begin{array}{c}
\frac{d \pi^{I}}{d p_{Q}^{I}} \\
\frac{d \pi^{E}}{d p_{Q}^{E}} \\
\frac{d \pi^{I}}{d p_{N}^{I}} \\
\frac{d \pi^{E}}{d p_{N}^{E}}
\end{array}\right]=\left\{\left[\begin{array}{cccc}
-2(1-\theta) & (1-\theta) & 0 & 0 \\
(1-\theta) & -2(1-\theta) & 0 & 0 \\
0 & 0 & -2 \theta & \theta \\
0 & 0 & \theta & -2 \theta
\end{array}\right]\left[\begin{array}{c}
p_{O}^{I} \\
p_{O}^{E} \\
p_{N}^{I} \\
p_{N}^{E}
\end{array}\right]+\left[\begin{array}{c}
(1-\theta)(t+s) \\
(1-\theta)(t-s) \\
\theta t \\
\theta t
\end{array}\right]\right\}\left(\frac{1}{2 t}\right)
$$

Since $\theta$ is interior, the block-diagonal system has full rank; thus, there is a unique solution. Moreover, one can easily verify the global concavity 
of the system, hence the FOC is sufficient. Solving the system yields prices claimed in the proposition, and market shares follow from substition into (12). Moreover, by inspection, $p_{O}^{E}<p_{N}^{E}$ holds; thus, the information constraint on the entrant is non-binding.

Proof of Proposition 2: With the pricing constraint, the incumbent's problem can be written in Kuhn-Tucker form:

$$
\mathcal{L}_{\mathcal{I}}=(1-\theta) \tilde{x}_{O} p_{O}^{I}+\theta \tilde{x}_{N} p_{N}^{I}-\lambda\left(\left|p_{O}^{I}-p_{N}^{I}\right|-\Delta\right)
$$

The entrant's problem remains unchanged. Consider first the case where the constraint is non-binding, i.e. $\lambda=0$. In this case, the first order conditions remain as in proposition 1 . We have $p_{O}^{* I}-p_{N}^{* I}=\frac{s}{3}$; for this solution to be in the feasible set, we must have $\Delta \geq \frac{s}{3}$.

Suppose now the constraint binds $(\lambda \neq 0)$. After substitution of the constraint, we obtain the system of first-order conditions

$$
\left[\begin{array}{c}
\frac{d \pi^{I}}{d p_{N}^{I}} \\
\frac{d \pi^{I}}{d p_{Q}^{I}} \\
\frac{d \pi^{E}}{d p_{N}^{E}}
\end{array}\right]=\left\{\left[\begin{array}{ccc}
-2 & (1-\theta) & 0 \\
(1-\theta) & -2(1-\theta) & 0 \\
\theta & 0 & -2 \theta
\end{array}\right]\left[\begin{array}{c}
p_{N}^{I} \\
p_{O}^{E} \\
p_{N}^{E}
\end{array}\right]+\left[\begin{array}{c}
2 \Delta(\theta-1)+s(1-\theta)+t \\
(\Delta+t)(1+\theta)-s(1-\theta) \\
\theta t
\end{array}\right]\right\}\left(\frac{1}{2 t}\right)
$$

Solving, analogously to proposition 1, the system and substituting back into the constraint yields prices and, through (1-2) the marginal consumers as claimed.

Proof of Result 1: By inspection of proposition 1, both firms charge different prices to each consumer group.

Proof of Result 2: The price wedge of the entrant is given by

$$
\delta_{E}=\left|p_{O}^{* E}-p_{N}^{* E}\right|=\frac{s-\Delta}{2}
$$

which is decreasing in $\Delta$. Hence regulation - lower $\Delta$-causes the price wedge to increase. 
Proof of Result 4: The derivative of consumer surplus (equation 8) is given by

$$
\begin{aligned}
\frac{d C S}{d \Delta} & =(1-\theta)\left(\int_{0}^{\tilde{x}_{O}}-\frac{d p_{O}^{* I}}{d \Delta} d x+\int_{\tilde{x}_{O}}^{1}-\frac{d p_{O}^{* E}}{d \Delta} d x\right) \\
& +\theta\left(\int_{0}^{\tilde{x}_{N}}-\frac{d p_{N}^{* I}}{d \Delta} d x+\int_{\tilde{x}_{N}}^{1}-\frac{d p_{N}^{* E}}{d \Delta} d x\right) \\
& =-\frac{(s-\Delta)(1-\theta) \theta}{8 t}<0
\end{aligned}
$$

where the first equality is by piece-wise differentiating the indirect utility function, depending on which firm the consumer purchases from and at what price. After substituting from proposition 2 and simplifying, one obtains the second equality; it is definitely signed since $\Delta \in\left[0, \frac{s}{3}\right]$.

Proof of Result 5: Producer surplus being the sum of individual firm profits $\left(P S=\Pi_{I}^{*}+\Pi_{E}^{*}\right)$, I proceed first to analyse how discrimination affects entrant and incumbent respectively. Taking derivatives of equation (3) around equilibrium values of proposition 2 , we have

$$
\begin{aligned}
\frac{d \Pi_{I}^{*}}{d \Delta} & =(1-\theta)\left(\int_{0}^{\tilde{x}_{O}} \frac{d p_{O}^{* I}}{d \Delta} d x+\frac{d \tilde{x}_{O}}{d \Delta} p_{O}^{* I}\right) \\
& +\theta\left(\int_{0}^{\tilde{x}_{N}} \frac{d p_{N}^{* I}}{d \Delta} d x+\frac{d \tilde{x}_{N}}{d \Delta} p_{N}^{* I}\right) \\
& =\frac{(s-2 \Delta)(1-\theta) \theta}{4 t}>0
\end{aligned}
$$

Since $\Delta \in\left[0, \frac{s}{3}\right]$, as before, the expression is definitely signed and the incumbent benefits from HBPD. Turning to the entrant,

$$
\begin{aligned}
\frac{d \Pi_{E}^{*}}{d \Delta} & =(1-\theta)\left(\int_{\tilde{x}_{O}}^{1} \frac{d p_{O}^{* E}}{d \Delta} d x-\frac{d \tilde{x}_{O}}{d \Delta} p_{O}^{* E}\right) \\
& +\theta\left(\int_{\tilde{x}_{N}}^{1} \frac{d p_{N}^{* E}}{d \Delta} d x-\frac{d \tilde{x}_{N}}{d \Delta} p_{N}^{* E}\right) \\
& =-\frac{(s-\Delta)(1-\theta) \theta}{4 t}<0
\end{aligned}
$$


Finally, combining the results, we have

$$
\begin{aligned}
\frac{d P S}{d \Delta} & =\frac{d \Pi_{I}^{*}}{d \Delta}+\frac{d \Pi_{E}^{*}}{d \Delta} \\
& =-\frac{\Delta(1-\theta) \theta}{4 t}
\end{aligned}
$$

Thus price discrimination harms industry and entrant profile, while benefiting the incumbent as claimed. Finally, since costs are normalised to zero, industry profit equals total revenue. Thus average prices fall if and only if industry profits fall; since industry profits fall, this establishes the "procompetitive" effect of history-based price discrimination.

Proof of Result 6: After simplifying - prices are just a transfer from consumers to producer, and hence do not enter social welfare - we have:

$$
\begin{aligned}
W & =(1-\theta)\left(\int_{0}^{\tilde{x}_{O}} \beta-t x d x+\int_{\tilde{x}_{O}}^{1} \beta-t(1-x)-s d x\right) \\
& +\theta\left(\int_{0}^{\tilde{x}_{N}} \beta-t x d x+\int_{\tilde{x}_{N}}^{1} \beta-t(1-x) d x\right)
\end{aligned}
$$

Differentiating with respect to $\Delta$ around the equilibrium values yields

$$
\begin{aligned}
\frac{d W}{d \Delta} & =(1-\theta) \frac{d \tilde{x}_{O}}{d \Delta}\left(t\left(1-2 \tilde{x}_{O}\right)+s\right)+\theta \frac{d \tilde{x}_{N}}{d \Delta}\left(t\left(1-2 \tilde{x}_{N}\right)\right) \\
& =-\frac{\Delta(1-\theta) \theta}{4 t} \leq 0
\end{aligned}
$$

\section{References}

Bouckaert, J., Degryse, H., Dijk, T., 2013. Bertrand competition with an asymmetric no-discrimination constraint. The Journal of Industrial Economics 61 (1), 62-83.

Chen, Y., 1997. Paying customers to switch. Journal of Economics \& Management Strategy 6 (4), 877-897.

Chen, Y., 2008. Dynamic price discrimination with asymmetric firms. The Journal of Industrial Economics 56 (4), 729-751. 
Corts, K. S., 1998. Third-degree price discrimination in oligopoly: all-out competition and strategic commitment. The RAND Journal of Economics, 306-323.

Esteves, R.-B., 2009. A survey on the economics of behaviour-based price discrimination. NIPE Working Paper 5/2009.

Fudenberg, D., Tirole, J., 2000. Customer poaching and brand switching. The RAND Journal of Economics 31 (4), 634-657.

Fudenberg, D., Villas-Boas, J., Hendershott, T., 2006. Behavior-based price discrimination and customer recognition. Handbook on economics and information systems 1, 377-436.

Gehrig, T., Shy, O., Stenbacka, R., 2011. History-based price discrimination and entry in markets with switching costs: a welfare analysis. European Economic Review 55 (5), 732-739.

Gehrig, T., Shy, O., Stenbacka, R., 2012. A welfare evaluation of historybased price discrimination. Journal of Industry, Competition and Trade $12(4), 373-393$.

Geradin, D., Kuschewsky, M., 2013. Competition law and personal data: Preliminary thoughts on a complex issue, available online at http://papers . ssrn.com/sol3/papers.cfm?abstract_id=2216088.

Geradin, D., Petit, N., 2005. Price discrimination under ec competition law. In: Swedish Competition Authority (Ed.), The pros and cons of price discrimination. pp. 21-64.

Hoernig, S., 2008. Tariff-mediated network externalities: is regulatory intervention any good? CEPR Discussion Paper No. 6866.

Hoernig, S., Inderst, R., Valletti, T. M., 2014. Calling circles: Network competition with non-uniform calling patterns. The RAND Journal of Economics, 155-175.

Hviid, M., Price, C. W., 2012. Non-discrimination clauses in the retail energy sector. The Economic Journal 122 (562), F236-F252.

Inderst, R., Valletti, T. M., 2011. Buyer power and the "waterbed effect". The Journal of Industrial Economics 59 (1), 1-20. 
Karlinger, L., Motta, M., 2012. Exclusionary pricing when scale matters. The Journal of Industrial Economics 60 (1), 75-103.

Layson, S. K., 1998. Third-degree price discrimination with interdependent demands. The Journal of Industrial Economics 46 (4), 511-524.

Papandropoulos, P., 2007. How should price discrimination be dealt with by competition authorities? Revue des droits de la concurrence (3), 34-38.

Peitz, M., 2005. Asymmetric regulation of access and price discrimination in telecommunications*. Journal of Regulatory Economics 28 (3), 327-343.

Rosoff, M., 2010. Microsoft paying customers to switch from salesforce.com. The Business Insider, December 6th 2010. Available online at http://www.businessinsider.com/ microsoft-paying-customers-to-switch-from-salesforcecom-2010-12.

Swedish Competition Authority (Ed.), 2005. The pros and cons of price discrimination.

Telecommunications Management Group, Inc., 2011. On-net/off-net price differentiation: Review of international precedent.

Thisse, J.-F., Vives, X., 1988. On the strategic choice of spatial price policy. The American Economic Review, 122-137.

\section{Acknowledgements}

This paper originated in chapter 2 of my $2013 \mathrm{PhD}$ thesis "Essays in Industrial Organization and Behaviour" at the European University Institute. I thank Piero Gottardi and Domenico Menicucci for supervision. Steffen Hoernig, Thomas Gehrig, Andrea Mattozzi, Arevik Mkrtchyan, Piotr Spiewanowski, Salvatore Piccolo and Tommaso Valetti provided very valuable comments. Thanks also to seminar participants in Florence. Financial support from the German Academic Exchange Service (DAAD) and the EUI Thesis Completion Year Grant is gratefully acknowledged. 
1. L. Colombo, H. Dawid, Strategic Location Choice under Dynamic Oligopolistic Competition and Spillovers, Novembre 2013.

2. M. Bordignon, M. Gamalerio, G. Turati, Decentralization, Vertical Fiscal Imbalance, and Political Selection, Novembre 2013.

3. M. Guerini, Is the Friedman Rule Stabilizing? Some Unpleasant Results in a Heterogeneous Expectations Framework, Novembre 2013.

4. E. Brenna, C. Di Novi, Is caring for elderly parents detrimental to women's mental health? The influence of the European North-South gradient, Novembre 2013.

5. F. Sobbrio, Citizen-Editors' Endogenous Information Acquisition and News Accuracy, Novembre 2013.

6. P. Bingley, L. Cappellari, Correlation of Brothers Earnings and Intergenerational Transmission, Novembre 2013.

7. T. Assenza, W. A. Brock, C. H. Hommes, Animal Spirits, Heterogeneous Expectations and the Emergence of Booms and Busts, Dicembre 2013.

8. D. Parisi, Is There Room for 'Fear' as a Human Passion in the Work by Adam Smith?, Gennaio 2014.

9. E. Brenna, F. Spandonaro, Does federalism induce patients' mobility across regions? Evidence from the Italian experience, Febbraio 2014.

10. A. Monticini, F. Ravazzolo, Forecasting the intraday market price of money, Febbraio 2014.

11. Tiziana Assenza, Jakob Grazzini, Cars Hommes, Domenico Massaro, $P Q$ Strategies in Monopolistic Competition: Some Insights from the Lab, Marzo 2014.

12. R. Davidson, A. Monticini, Heteroskedasticity-and-Autocorrelation-Consistent Bootstrapping, Marzo 2014.

13. C. Lucifora, S. Moriconi, Policy Myopia and Labour Market Institutions, Giugno 2014.

14. N. Pecora, A. Spelta, Shareholding Network in the Euro Area Banking Market, Giugno 2014.

15. G. Mazzolini, The economic consequences of accidents at work, Giugno 2014.

16. M. Ambrosanio, P. Balduzzi, M. Bordignon, Economic crisis and fiscal federalism in Italy, Settembre 2014.

17. P. Bingley, L. Cappellari, K. Tatsiramos, Family, Community and Long-Term Earnings Inequality, Ottobre 2014.

18. S. Frazzoni, M. L. Mancusi, Z. Rotondi, M. Sobrero, A. Vezzulli, Innovation and export in SMEs: the role of relationship banking, Novembre 2014.

19. H. Gnutzmann, Price Discrimination in Asymmetric Industries: Implications for Competition and Welfare, Novembre 2014. 